\title{
A NEW APPROACH TO DTC METHOD FOR BLDC MOTOR ADJUSTABLE SPEED DRIVES
}

\author{
Fatih Korkmaz \\ Department of Electric-Electronic Engineering, Çankırı Karatekin University, \\ Uluyazı Kampüsü, Çankırı, Turkey
}

\begin{abstract}
This paper proposes a new approach to direct torque control (DTC) method for brushless direct current $(B L D C)$ motor drives. In conventional DTC method, two main reference parameters are used as: flux and torque. In this paper, the new approach has been proposed to improve the $B L D C$ motor dynamic performance. A main difference from the conventional method of it was that only one reference parameter (speed) was used to control the BLDC motor and the second control parameter (flux) was obtained from speed error through the proposed control algorithm. Thus, the DTC performance has been especially improved on systems which need variable speed and torque during operation, like electric vehicles. The dynamic models of the $B L D C$ and the DTC method have been created on Matlab/Simulink. The proposed method has been confirmed and verified by the dynamic simulations on different working conditions.
\end{abstract}

\section{KEY WORDS}

Brushless machines, Direct torque control, Vector control, Torque control

\section{INTRODUCTION}

In recent years, the BLDC motors applications become more popular in industrial and daily utilization, like CNC machines, servo systems and electric vehicles. The main reasons of the increasing on popularity of BLDC motors, in other words, main advantages of the BLDC motors, can be listed as follows[1-4]:

- High efficiencies

- High power densities

- High starting torque

- Wide speed ranges

- Linear torque and speed characteristics

- Low maintenance and works in any condition

The BLDC motors not only have advantages of conventional DC motors but also have advantages of AC motors as can be seen from the list. Because, they have the AC motor mechanical structures -no brushes or collectors-while they have the DC motors electrical structures.

The DTC method was developed by Takahashi in the middle of the 1980s, for three phase induction motors. The DTC method converts three phase parameters of the motor (three phase voltage and currents) to two phase independent vector components with Clarke transformation, thus, it proposes

David C. Wyld et al. (Eds) : DBDM, CICS, CSIP, AI\&FL, SCOM, CSE, CCNET-2016 
control of every components separately, like conventional DC motors. Although, it was developed for the induction motors, it has been applied many other motor types like permanent magnet AC motors, BLDC motors, switched reluctance motors, linear motors[5-6].

In literature, many kind of BLDC motor drive methods can be found. In [7], artificial neural networks based method was used in modeling of BLDC to get the maximum power consumption. Very simple and effective three-level neutral point clamped inverter was proposed to drive axial flux BLDC motors, in [8]. Field Programmable Gate Array (FPGA) based BLDC motor driver with using digital pulse-width modulation (PWM) is presented in [9]. In addition, several different methods, which based of the DTC, were studied in BLDC drivers. Reference [10] proposes the DTC method for matrix converter fed BLDC motor. The DTC of BLDC motor method using with four-switch inverter in constant torque region was proposed in [11].

In this paper, a new approach to the DTC method has been proposed for small sized electric vehicles that work in variable speed and torque conditions, naturally. In the proposed method, optimum stator flux reference value was obtained by PI controller with usage of the speed error. The dynamic model of the proposed method was developed with Matlab/Simulink. The dynamic simulations were performed and results were presented to illustrate the validity of the proposed method.

\section{DIRECT TORQUE CONTROL OF BLDC}

The BLDC motor has three phase stator windings with permanent magnet rotor and electrical model of the motor that connected with PWM inverter, is given in Fig. 1[12].

Voltage equations of the motor can be obtained by the following equation;

$$
\left[\begin{array}{c}
V_{a} \\
V_{b} \\
V_{c}
\end{array}\right]=\left[\begin{array}{ccc}
R & 0 & 0 \\
0 & R & 0 \\
0 & 0 & R
\end{array}\right]\left[\begin{array}{c}
i_{a} \\
i_{b} \\
i_{c}
\end{array}\right]+\left[\begin{array}{ccc}
\mathrm{L} & 0 & 0 \\
0 & L & 0 \\
0 & 0 & L
\end{array}\right] \frac{d}{d t}\left[\begin{array}{c}
i_{a} \\
i_{b} \\
i_{c}
\end{array}\right]+\left[\begin{array}{c}
\mathrm{e}_{a} \\
e_{b} \\
e_{c}
\end{array}\right]
$$

Where $V_{a}, V_{b}, V_{c}$ are phase voltages, $R$ is resistance, $L$ is phase inductance, $i_{a}, i_{b}, i_{c}$ are phase currents and $\mathrm{e}_{\mathrm{a}}, \mathrm{e}_{\mathrm{b}}, \mathrm{e}_{\mathrm{c}}$ are back EMFs.

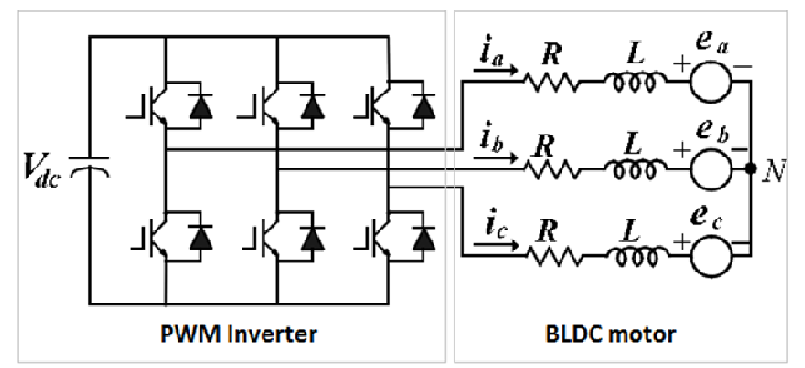

Figure 1. Electrical model of the motor that connected with PWM inverter

The mechanical moment equation of the motor given by the following equation;

$$
T_{e}=T_{L}+B \omega_{m}+j \frac{d \omega_{m}}{d t}
$$

$\mathrm{T}_{\mathrm{e}}$ and $\mathrm{T}_{\mathrm{L}}$ describes generated electromagnetic torque and load torque, respectively. $\mathrm{B}$ is the friction 
coefficient, $\mathrm{j}$ is the inertia and $\omega_{\mathrm{m}}$ is the angular velocity of rotor[13].

The DTC method needs to transformation of the three phase motor parameters to two phase. In this transformation, electrical parameters of the motor (voltages, currents, back emf) should to be transformed to stationary reference frame and it can also be named as $\alpha-\beta$ transformation or Clarke transformation in many sources. The Clarke transformation matrix is given (3).

$$
\left[\begin{array}{l}
f_{\alpha} \\
f_{\beta}
\end{array}\right]=\frac{2}{3}\left[\begin{array}{ccc}
1 & -\frac{1}{2} & -\frac{1}{2} \\
0 & \frac{\sqrt{3}}{2} & -\frac{\sqrt{3}}{2}
\end{array}\right]\left[\begin{array}{l}
f_{a} \\
f_{b} \\
f_{c}
\end{array}\right]
$$

Where, $\mathrm{f}_{\alpha}, \mathrm{f}_{\beta}$ are $\alpha-\beta$ components of motor parameters, and $\mathrm{f}_{\mathrm{a}}, \mathrm{f}_{\mathrm{b}}, \mathrm{f}_{\mathrm{c}}$ are the abc frame components [14].

With the transforming of the three phase parameters of the motor, $\alpha-\beta$ components of the phase voltages can be written as:

$$
\begin{aligned}
& \mathrm{v}_{\mathrm{s} \alpha}=\mathrm{R}_{\mathrm{s}} \mathrm{i}_{\mathrm{s} \alpha}+\mathrm{L}_{\mathrm{s}} \frac{\mathrm{di}_{\mathrm{s} \alpha}}{\mathrm{dt}}+\mathrm{e}_{\alpha} \\
& \mathrm{v}_{\mathrm{s} \beta}=\mathrm{R}_{\mathrm{s}} \mathrm{i}_{\mathrm{s} \beta}+\mathrm{L}_{\mathrm{s}} \frac{\mathrm{di}_{\mathrm{s} \beta}}{\mathrm{dt}}+\mathrm{e}_{\beta}
\end{aligned}
$$

Where $\mathrm{v}_{\mathbf{s} \alpha}, \mathrm{v}_{\mathrm{s} \beta}$ are the stator voltages, $\mathrm{i}_{\mathrm{s} \alpha}, \mathrm{i}_{\mathrm{s} \beta}$ are the stator currents and $\mathrm{e}_{\alpha}, \mathrm{e}_{\beta}$ are back emf in the $\alpha-\beta$ referance frame.

In the DTC scheme, stator flux components are obtained from $\alpha-\beta$ components of the measured stator voltages and currents as given below[15]:

$$
\begin{aligned}
& \lambda_{\mathrm{s} \alpha}=\int\left(\mathrm{v}_{\mathrm{s} \alpha}-\mathrm{R}_{\mathrm{s}} \mathrm{i}_{\mathrm{s} \alpha}\right) \mathrm{dt} \\
& \lambda_{\mathrm{s} \beta}=\int\left(\mathrm{v}_{\mathrm{s} \beta}-\mathrm{R}_{\mathrm{s}} \mathrm{i}_{\mathrm{s} \beta}\right) \mathrm{dt}
\end{aligned}
$$

The magnitude of the flux can be calculated with;

$$
\lambda=\sqrt{\lambda_{\mathrm{s} \alpha}^{2}+\lambda_{\mathrm{s} \beta}^{2}}
$$

and position of the stator flux vector can be calculated with;

$$
\theta=\arctan \frac{\lambda_{\mathrm{s} \beta}}{\lambda_{\mathrm{s} \alpha}}
$$

In the conventional DTC (C-DTC) method, control algorithms works with two separate reference values as torque (or speed) and flux references. Because, in idea of the DTC, stator flux vector has two components ( $\alpha-\beta$ components) and they can be controlled independently from each other. One of them controls flux, while the other one controls torque. In generally, flux reference is kept constant and the speed control of the motor can be achieved by setting up the torque reference value. This approach is very appropriate for constant torque-variable speed applications. The conventional DTC block diagram is given in Fig. 2. 


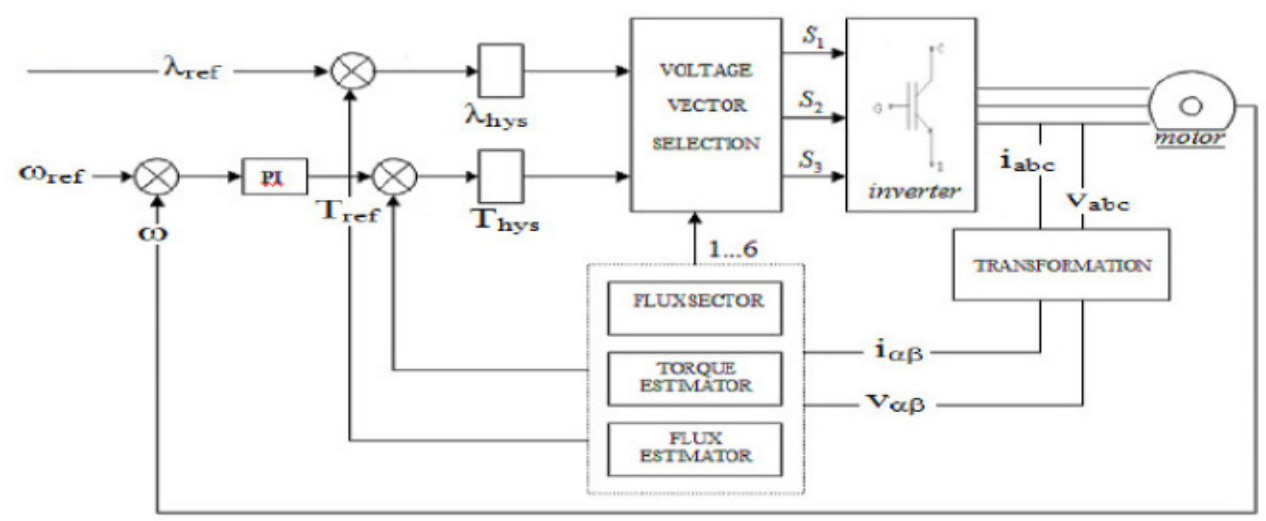

Figure 2. The conventional DTC block diagram

\section{AdAPTIVE FLUX BASED METHOD}

A main difference from the conventional method of it was that only one reference parameter (speed) was used to control the BLDC motor and the second control parameter (flux) was obtained from speed error through the proposed control algorithm. Thus, the DTC performance has been especially improved on systems which need variable speed and torque during operation, like electric vehicles. The dynamic models of the BLDC and the DTC method have been created on Matlab/Simulink. The proposed DTC method Simulink block diagram is given in Fig. 3.

In dynamic simulations, the BLDC motor was performed under two different working conditions. The parameters of the blocks and the motor that used in dynamic simulations were given in appendix. Total simulation time was $1 \mathrm{sec}$. for all conditions. The sampling time was $10 \mu \mathrm{s}$.

The motor load constant $(5 \mathrm{Nm})$ and the speed reference was changed $2000 \mathrm{rpm}$ to $400 \mathrm{rpm}$ at 0,5 . sec. in first working condition. The speed and the torque responses of the motor were given in Fig. 4 and Fig. 5, respectively.

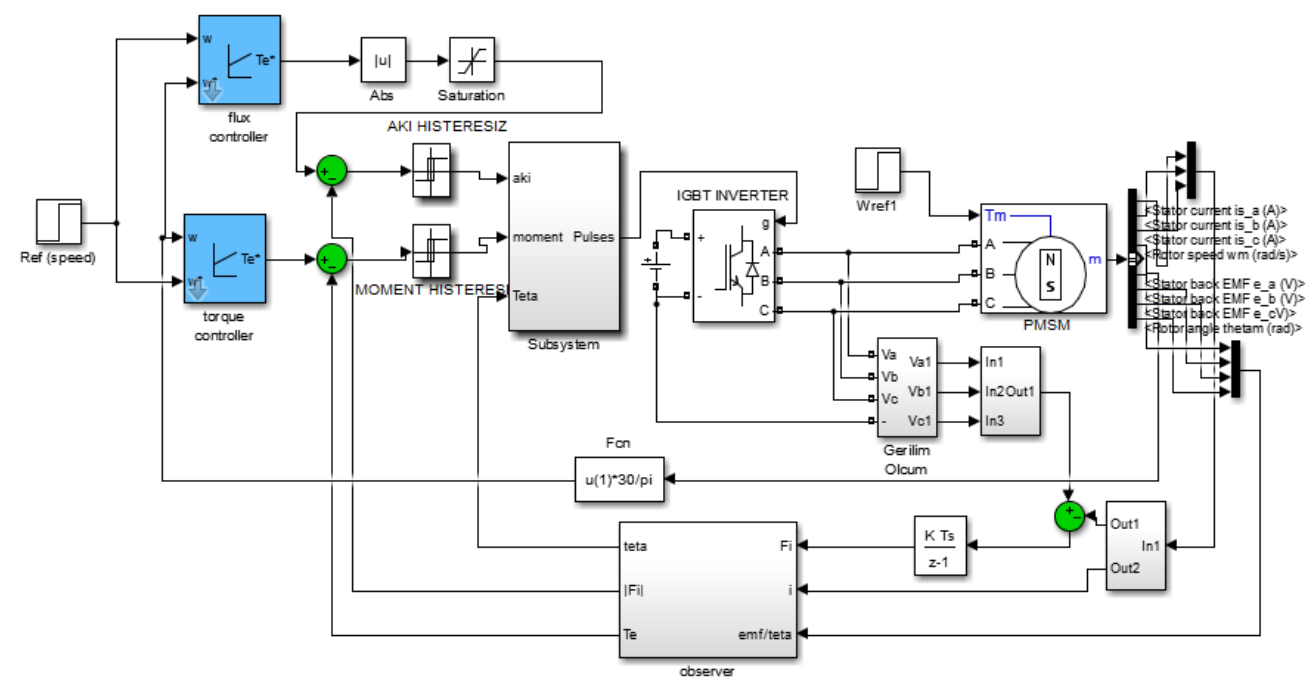

Figure 3. The proposed DTC Simulink block diagram 

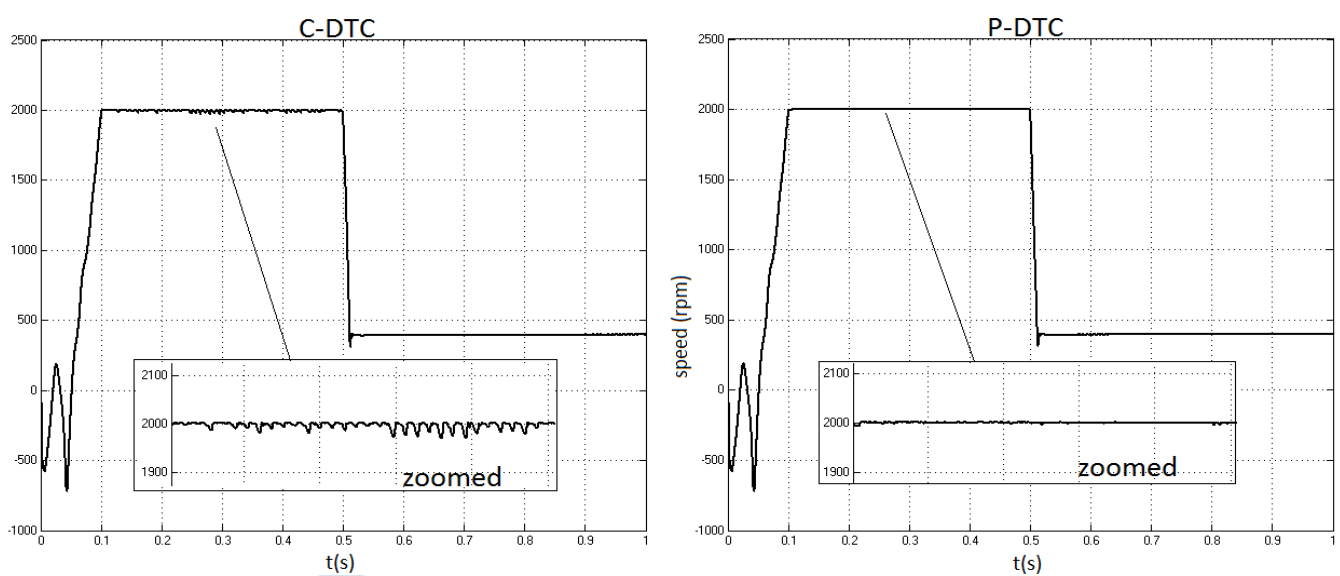

Figure 4. Speed responses of the BLDC in variable speed-constant load
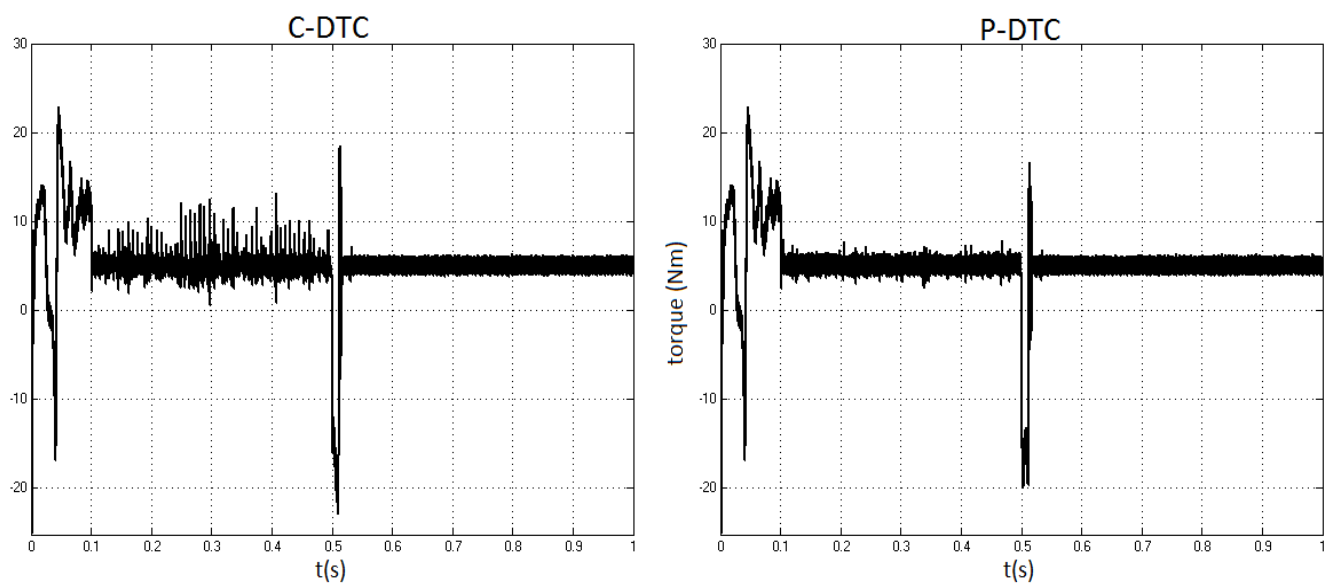

Figure 5. Torque responses of the BLDC in variable speed-constant load
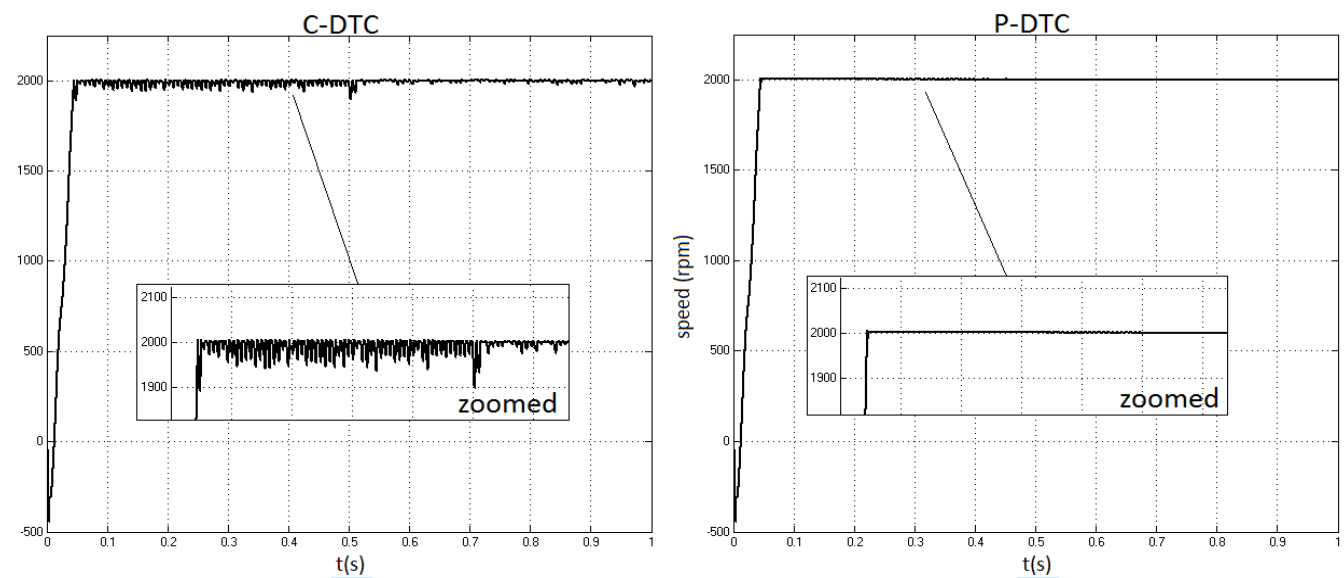

Figure 6. Speed responses of the BLDC in variable torque-constant speed 

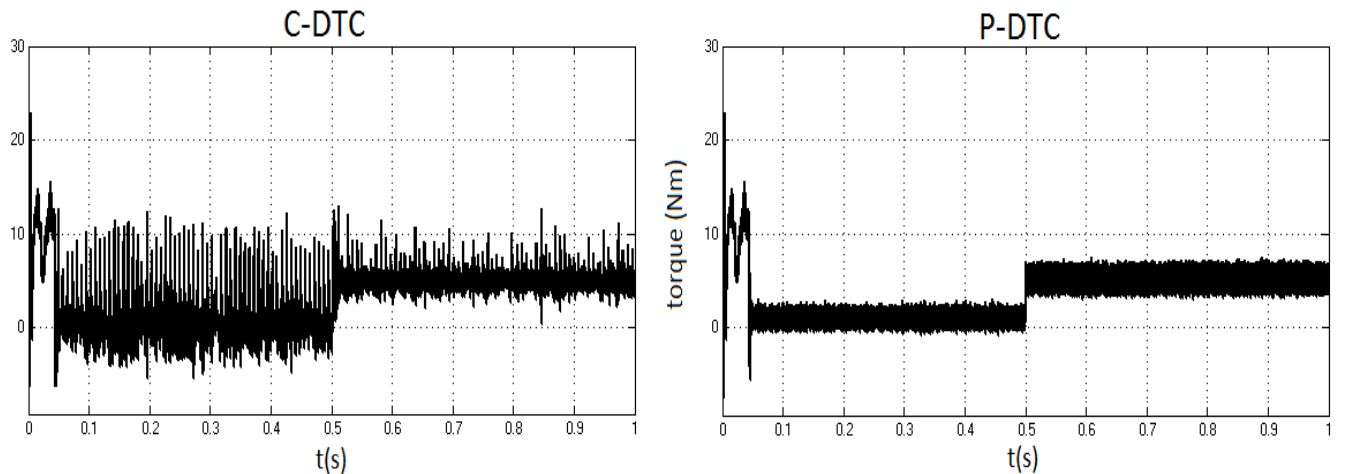

Figure 7. Torque responses of the BLDC in variable torque-constant speed

In the second test, the motor was simulated at constant speed reference $(2000 \mathrm{rpm})$ and the torque reference was changed to $1 \mathrm{Nm}$ to $5 \mathrm{Nm}$ at 0,5 . sec. The speed and the torque responses of the motor were given in Fig. 6 and Fig. 7, respectively.

It can be seen in from figures (Fig. 4-Fig. 7) that, the BLDC motor speed and torque responses were improved with the P-DTC method. The torque and speed ripples reduced remarkably with the PDTC method especially in high speed reference values. In $400 \mathrm{rpm}$ speed reference, the motor dynamic behaviors were almost same with both methods.

\section{CONCLUSIONS}

Over the last decades, the BLDC motors have been used many industrial applications and it has gain great popularity between electric motors. On the other hand, the DTC is well-known high performance control method not only for induction motors but also many other motor types. This paper presents a new perspective to the conventional DTC method. The proposed DTC method applied to the BLDC motors which considered drives small size electric vehicles. These vehicles works in variable speed and torque conditions with single reference input: speed. The conventional DTC method was modified with the adding of second PI controller that produces optimum flux reference. In order to test the validity and applicability of the proposed method, dynamic simulations were been performed under different working conditions and results were presented. The simulations results showed that the proposed method reduced remarkably the speed and the torque ripples when compared conventional DTC method. The proposed method had also very simple structure to apply the conventional DTC and its extra computational load to the controller was almost zero.

\section{APPENDIX}

The parameters of the blocks and the motor that used in dynamic simulations are, DC bus voltage $400 \mathrm{~V}$, stator phase resistance, Rs $(\mathrm{ohm})=0.45$, stator phase inductance Ls $(\mathrm{H})=8.5 \mathrm{e}-3$, flux hysteresis band limits $= \pm 0.005$, torque hysteresis band limits $= \pm 0.02$, stator flux reference $=0.32$ weber, sampling time $10 \mu \mathrm{sec}$.

\section{REFERENCES}

[1] C. Xia, Z. Li, and T. Shi, "A Control Strategy for Four-Switch Three-Phase Brushless DC Motor Using Single Current Sensor”, Industrial Electronics, IEEE Transactions on , vol.56, no.6, pp. 2058-2066, June 2009. 
[2] Z. Xiaofeng, L. Zhengyu, "A new BLDC motor drives method based on BUCK converter for torque ripple reduction,", Power Electronics and Motion Control Conference, 2006. IPEMC 2006. CES/IEEE 5th International, vol.2, no., pp.1-4, 14-16 Aug. 2006

[3] I. Topaloglu, F. Korkmaz, H. Mamur, R. Gurbuz, "Closed-Loop speed control of PM-BLDC motor fed by six step inverter and effects of inertia changes for desktop CNC machine" Elektronika IR Elektrotechnika, vol. 19, no 1, pp. 7-10, 2013.

[4] I. Tarimer, A. Akpunar, R. Gurbuz, "Design of a direct sliding gearless electrical motor for an ergonomic electrical wheelchair”, Elektronika IR Elektrotechnika, no 3, pp. 75-80, 2008.

[5] I. Takahashi and T. Noguchi , "A new quick-response and high efficiency control strategy of an induction motor" IEEE Transactions on Industrial Applications, vol.I A-22, no.5, pp. 820-827, 1986.

[6] F. Korkmaz, I. Topaloglu, R. Gurbuz, "Simulink model of vector controlled linear induction motor with end effect for electromagnetic launcher system”, Elektronika IR Elektrotechnika, vol. 20, no 1, pp. 29 32, 2014.

[7] M. Nizam, A. Mujianto, H. Triwaloyo, Inayati, "Modelling on BLDC motor performance using artificial neural network (ANN)", Rural Information \& Communication Technology and Electric-Vehicle Technology (rICT \& ICeV-T), 2013 Joint International Conference on , vol., no., pp.1-4, 26-28 Nov. 2013.

[8] S. De, M. Rajne, S. Poosapati, C. Patel, K. Gopakumar, "Low-inductance axial flux BLDC motor drive for more electric aircraft", Power Electronics, IET , vol.5, no.1, pp.124-133, January 2012.

[9] A. Tashakori, M. Hassanudeen, M. Ektesabi, "FPGA based controller drive of BLDC motor using digital PWM technique", Power Electronics and Drive Systems (PEDS), 2015 IEEE 11th International Conference on , vol., no., pp.658-662, 9-12 June 2015.

[10] R. Muthu, M.S. Kumaran, L.A. Rajaraman, P. Ganesh, P. Reddy, "Direct Torque Control of matrix converter fed BLDC motor", Power Electronics (IICPE), 2014 IEEE 6th India International Conference on , vol., no., pp.1-6, 8-10 Dec. 2014.

[11] S.B. Ozturk, W.C. Alexander, H.A. Toliyat, "Direct torque control of four-switch brushless DC Motor with non-sinusoidal back-EMF", Power Electronics Specialists Conference, 2008. PESC 2008. IEEE, vol., no., pp.4730-4736, 15-19 June 2008.

[12] W.S. Im, W. Liu, J.M. Kim, "Sensorless control of 3-phase BLDC motors using DC current model", Energy Conversion Congress and Exposition (ECCE), 2014 IEEE , vol., no., pp.4484-4490, 14-18 Sept. 2014.

[13] P.K. Girija, A. Prince, "Robustness evaluation of SMO in sensorless control of BLDC motor under DTC scheme", Power Signals Control and Computations (EPSCICON), 2014 International Conference on , vol., no., pp.1-6, 6-11 Jan. 2014.

[14] F. Korkmaz, I. Topaloglu, M.F. Cakir, R. Gurbuz, "Comparative performance evaluation of FOC and DTC controlled PMSM drives", Power Engineering, Energy and Electrical Drives (POWERENG), 2013 Fourth International Conference on , vol., no., pp.705-708, 13-17 May 2013.

[15] F. Korkmaz, M.F. Cakir, Y. Korkmaz, I. Topaloglu, "Fuzzy based stator flux optimizer design for direct torque control", International Journal of Instrumentation and Control Systems (IJICS), vol.2, no.4, pp. 41-49, October 2012. 


\section{AUTHORS}

Fatih Korkmaz received the B.S., M.S., and Ph.D. degrees in electrical education from Gazi University, Ankara, Turkey, in 2000,2004 and 2011, respectively. His current major research interests include design, control and applications of motor drive systems. From 2013, he is an assistant professor in Çankırı Karatekin University, Turkey.

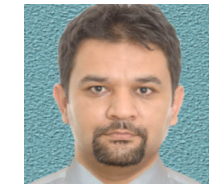

